\title{
Practice Parameter: Evaluation of distal symmetric polyneuropathy: Role of autonomic testing, nerve biopsy, and skin biopsy (an evidence-based review)
}

Report of the American Academy of Neurology, American Association of Neuromuscular and Electrodiagnostic Medicine, and American Academy of Physical Medicine and Rehabilitation 0 a

J.D. England, MD

G.S. Gronseth, MD, FAAN

G. Franklin, MD

G.T. Carter, MD

L.J. Kinsella, MD

J.A. Cohen, MD

A.K. Asbury, MD

K. Szigeti, MD, PhD

J.R. Lupski, MD, PhD

N. Latov, MD

R.A. Lewis, MD

P.A. Low, MD

M.A. Fisher, MD

D.N. Herrmann, MD

J.F. Howard, Jr., MD

G. Lauria, MD

R.G. Miller, MD

M. Polydefkis, MD,

MHS

A.J. Sumner, MD

Address correspondence and reprint requests to the American Academy of Neurology, 1080 Montreal Avenue, St. Paul, MN 55116

guidelines@aan.com

Supplemental data at www.neurology.org

See page 185

\section{ABSTRACT}

Background: Distal symmetric polyneuropathy (DSP) is the most common variety of neuropathy. Since the evaluation of this disorder is not standardized, the available literature was reviewed to provide evidence-based guidelines regarding the role of autonomic testing, nerve biopsy, and skin biopsy for the assessment of polyneuropathy.

Methods: A literature review using MEDLINE, EMBASE, and Current Contents was performed to identify the best evidence regarding the evaluation of polyneuropathy published between 1980 and March 2007. Articles were classified according to a four-tiered level of evidence scheme and recommendations were based upon the level of evidence.

Results and Recommendations: 1) Autonomic testing should be considered in the evaluation of patients with polyneuropathy to document autonomic nervous system dysfunction (Level B). Such testing should be considered especially for the evaluation of suspected autonomic neuropathy (Level B) and distal small fiber sensory polyneuropathy (SFSN) (Level C) A battery of validated tests is recommended to achieve the highest diagnostic accuracy (Level B).2) Nerve biopsy is generally accepted as useful in the evaluation of certain neuropathies as in patients with suspected amyloid neuropathy, mononeuropathy multiplex due to vasculitis, or with atypical forms of chronic inflammatory demyelinating polyneuropathy (CIDP). However, the literature is insufficient to provide a recommendation regarding when a nerve biopsy may be useful in the evaluation of DSP (Level U). 3) Skin biopsy is a validated technique for determining intraepidermal nerve fiber density and may be considered for the diagnosis of DSP, particularly SFSN (Level C). There is a need for additional prospective studies to define more exact guidelines for the evaluation of polyneuropathy. Neurology ${ }^{\circledR} 2009 ; 72: 177-184$

\section{GLOSSARY}

AAN = AmericanAcademy of Neurology; AANEM = American Academy of Neuromuscular and Electrodiagnostic Medicine; AAPM\&R = American Academy ofPhysical Medicine and Rehabilitation; ART = autonomic reflex testing; $\mathbf{B R S I}=$ baroreflex sensitivity index; CASS = composite autonomic scoring scale; CIDP = chronic inflammatory demyelinating polyneuropathy; $\mathbf{D S F N}=$ distal small fiber neuropathy; DSP = distal symmetric polyneuropathy; EDx = electrodiagnosis; EFNS = European Federation of Neurological Societies; HRV = heart rate variability; IAN = idiopathic autonomic neuropathy; IENF = intraepidermal nerve fibers; MSNA = muscle sympathetic nerve activity; $\mathbf{N C S s}=$ nerve conduction studies; PGP 9.5 = protein-gene-product 9.5; $\mathbf{P N}=$ peripheral neuropathy; $\mathbf{R R T}$ = blood pressure recovery time; $\mathbf{Q A E}=$ quantitative autonomic examination; QSART = quantitative sudomotor axon reflex test; QSS = Quality Standards Subcommittee; QST = quantitative sensory testing; SFSN = small fiber sensory polyneuropathy; TST = thermoregulatory sweat testing.

Polyneuropathy is a relatively common neurologic disorder. ${ }^{1}$ The overall prevalence is approximately $2,400(2.4 \%)$ per 100,000 population, but in individuals older than 55 years, the prevalence rises to approximately $8,000(8 \%)$ per $100,000 .^{2,3}$ Since there are many etiologies of polyneuropathy, a logical clinical approach is needed for evaluation and management.

This practice parameter provides recommendations for the evaluation of distal symmetric polyneu-

e-Pub ahead of print on December 3, 2008, at www.neurology.org.

Published simultaneously in PM\&R and Muscle \& Nerve.

Authors' affiliations are listed at the end of the article.

The AAN Mission Statement, Classification of evidence, Classification of recommendations, and Conflict of Interest Statement (appendices e-1 through e-4), as well as references e1-e16, are available as supplemental data on the Neurology ${ }^{\circledR}$ Web site at www.neurology.org.

Approved by the Quality Standards Subcommittee on November 10, 2007; by the AAN Practice Committee on January 30, 2008; by the

Neuromuscular Guidelines Steering Committee on April 22, 2008; by the AAN Board of Directors on August 20, 2008; by the AANEM Board of

Directors on May 1, 2008; and by the AAPM\&R Board of Governors on April 7, 2008.

Disclosure: Author disclosures are provided at the end of the article. 
ropathy (DSP) based upon a prescribed review and analysis of the peer-reviewed literature. The parameter was developed to provide physicians with evidence-based guidelines regarding the role of autonomic testing, nerve biopsy, and skin biopsy for the assessment of polyneuropathy. The diagnosis of DSP should be based upon a combination of clinical symptoms, signs, and electrodiagnostic criteria as outlined in the previous case definition. ${ }^{1}$ See Mission statement (appendix e-1 on the Neurology ${ }^{\circledR}$ Web site at www.neurology.org) for details.

FORMATION OF EXPERT PANEL The Polyneuropathy Task Force included 19 physicians with representatives from the American Academy of Neurology (AAN), the American Academy of Neuromuscular and Electrodiagnostic Medicine (AANEM), and the American Academy of Physical Medicine and Rehabilitation (AAPM\&R). All of the task force members had extensive experience and expertise in the area of polyneuropathy. Additionally, four members had expertise in evidence-based methodology and practice parameter development. Two are current members (J.D.E., G.F.), and two are former members (G.S.G, R.G.M.) of the Quality Standards Subcommittee (QSS) of the AAN. The task force developed a set of clinical questions relevant to the evaluation of DSP, and subcommittees were formed to address each of these questions.

DESCRIPTION OF THE ANALYTIC PROCESS The literature search included OVID MEDLINE (1966 to March 2007), OVID Excerpta Medica (EMBASE; 1980 to March 2007), and OVID Current Contents (2000 to March 2007). The search included articles on humans only and in all languages. The search terms selected were peripheral neuropathy, polyneuropathy, and distal symmetric polyneuropathy. These terms were cross-referenced with the terms diagnosis, electrophysiology, autonomic testing, nerve biopsy, and skin biopsy.

Panel experts were asked to identify additional articles missed by the initial search strategy. Further, the bibliographies of the selected articles were reviewed for potentially relevant articles.

Subgroups of committee members reviewed the titles and abstracts of citations identified from the original searches and selected those that were potentially relevant to the evaluation of polyneuropathy. Articles deemed potentially relevant by any panel member were also obtained.

Each potentially relevant article was subsequently reviewed in entirety by at least three panel members. Each reviewer graded the risk of bias in each article by using the diagnostic test classification-of-evidence scheme (appendix e-2). In this scheme, articles at- taining a grade of Class I are judged to have the lowest risk of bias, and articles attaining a grade of Class IV are judged to have the highest risk of bias. Disagreements among reviewers regarding an article's grade were resolved through discussion. Final approval was determined by the entire panel. The AAN's method for determining the strength of recommendation was used (appendix e-3).

The QSS (AAN; appendix 1), the Practice Issues Review Panel (AANEM; appendix 2), and the Practice Guidelines Committee (AAPM\&R; appendix 3) reviewed and approved a draft of the article. The draft was next sent to members of the AAN, AANEM, and AAPM\&R for further review and then to Neurology ${ }^{\circledR}$ for peer review. Boards of the AAN, AANEM, and $A A P M \& R$ reviewed and approved the final version of the article. At each step of the review process, external reviewers' suggestions were explicitly considered. When appropriate, the expert panel made changes to the document

ANALYSIS OF EVIDENCE The search yielded 1,045 references with abstracts. After reviewing titles and abstracts, 106 articles were reviewed and classified.

Role of clinical autonomic testing in the evaluation of polyneuropathy. Autonomic nervous system dysfunction occurs in several phenotypes. It may occur as one component of a generalized polyneuropathy such as DSP of diabetes. Such polyneuropathies are usually diagnosed by a combination of neuropathic symptoms, decreased or absent ankle reflexes, decreased distal sensation, distal muscle weakness or atrophy, and abnormal nerve conduction studies (NCSs). ${ }^{1}$ The majority of these features constitute evidence of "large fiber" sensory and motor involvement. However, signs of autonomic nervous system involvement may also constitute findings indicative of DSP. In DSP with autonomic involvement, the most common clinical findings are abnormalities of sweating and circulatory instability in the feet. ${ }^{1,3}$

A second phenotype is that of an autonomic neuropathy such as in amyloidosis and autoimmune autonomic neuropathy, where autonomic nerves are affected disproportionately relative to somatic nerves. ${ }^{4}$ In these neuropathies, autonomic fibers can be affected in isolation and their involvement may precede somatic fiber involvement. ${ }^{5}$

A third relatively common phenotype is distal small fiber sensory polyneuropathy (SFSN), which can manifest as burning pain affecting the feet, often with allodynia and sometimes with erythromelalgia (red hot and painful skin). Involvement of autonomic and somatic $\mathrm{C}$ fibers usually occurs concurrently in small fiber polyneuropathy. 

the evaluation of polyneuropathy, and which tests have the highest sensitivity and specificity? Currently available autonomic tests can provide indices of cardiovagal, adrenergic, and postganglionic sudomotor function. As such, they provide indices for both parasympathetic and sympathetic autonomic function. Heart rate variability testing is a simple and reliable test of cardiovagal function. It detects the presence of diabetic polyneuropathy with nearly the same sensitivity as NCSs (Class II). ${ }^{6}$ Specificity is high $(97.5 \%)$ for identifying parasympathetic deficits if the recommended age-controlled values are used (Class II). ${ }^{7}$ Intrinsic cardiac disease can affect the results of this test, and this possibility must be considered in the interpretation.

Cardiovagal function can be evaluated using different indices in the time and frequency domains. ${ }^{8}$ There is no compelling evidence that one method is better than another or that the use of multiple indices confers any advantage. Heart rate variability to deep breathing is the most widely used test of cardiovagal function and has a specificity of approximately $80 \%$ (Class II)?

The vagal component of the baroreflex can be yaluated by quantitating the heart period response to induced changes in BP. A well-studied test is the modified Oxford method. ${ }^{10}$ The test consists of an evaluation of heart period responses to induced increases and decreases in arterial BP. The increase is evoked by IV phenylephrine and decrease by nitroprusside in incremental doses. Baroreflex sensitivity is defined by the slope of the heart period to BP relationship. Linearity is required $(\mathrm{R}>0.85)$. The advantage of this test is that it evaluates vagal baroreflex sensitivity; however, the disadvantage is that the test is invasive and not widely performed. Approximation of this method is possible by relating heart period alterations to changes in BP induced by the Valsalva maneuver. ${ }^{11}$ The sensitivity and specificity of invasive and noninvasive tests of baroreflex function are high, but these tests are not generally used in the study of neuropathy since their value is considered only additive to current tests of cardiovagal function (Class II). $4,9,12,13$

Thermoregulatory sweat testing (TST) is a sensitive test of sudomotor function that utilizes an indicator substance whose color changes upon exposure to sweat. ${ }^{14,15}$ The test results can be semiquantitated by estimating the percentage of skin surface that is anhidrotic. Since the test is tedious, messy, and timeconsuming, it is not routinely done. Additionally, TST is not able to distinguish between postganglionic, preganglionic, and central lesions. ${ }^{14,15}$ The most quantitative test of sudomotor function is the 
quantitative sudomotor axon reflex test (QSART). ${ }^{16}$ QSART is mediated by impulses traveling antidromically then orthodromically along the postganglionic sympathetic sudomotor axon. QSART can detect distal sudomotor loss with a sensitivity of 75-90\% (Class III)..$^{7,17-19}$ Several studies have demonstrated that QSART can determine sudomotor abnormalities with relatively high sensitivity and specificity in many types of polyneuropathies (Class II and III). ${ }^{4-7,16,17,19-21}$ In three Class III studies, QSART was shown capable of detecting distal small fiber polyneuropathy with a sensitivity of $>75 \%{ }^{17-19}$

Skin vasomotor reflexes assessed by monitoring skin blood flow using laser Doppler flowmeter have not been well studied. Limited data from one Class III study using this technique demonstrated an unacceptably large coefficient of variation. ${ }^{22}$

Analysis of the available Class II and III studies on autonomic testing indicates that a combination of autonomic reflex screening tests provides distinct advantages over single modality methods (table). The composite autonomic scoring scale (CASS), which includes QSART, orthostatic blood pressure, heart rate response to tilt, heart rate response to deep breathing, the Valsalva ratio, and beat-to-beat blood pressure measurements during phases $\mathrm{I}$ and IV of the Valsalva maneuver, tilt, and deep breathing, provides a useful 10-point scale of autonomic function (Class II). ${ }^{4,9}$ In a study of 78 patients with graded autonomic failure obtained by selecting approximately equal numbers of patients with multiple system atrophy, Parkinson disease, autonomic neuropathies, and idiopathic peripheral neuropathies, this combination of tests provided a noninvasive, sensitive, specific, and reproducible methodology for grading the degree of autonomic dysfunction (Class II). ${ }^{9}$

Conclusions. Autonomic testing is probably useful in documenting autonomic nervous system involvement in polyneuropathy (Class II and III). The sensitivity and specificity vary with the particular test. The utilization of the combination of autonomic reflex screening tests in the CASS probably provides the highest sensitivity and specificity for documenting autonomic dysfunction (Class II).

Recommendations. Autonomic testing should be considered in the evaluation of patients with polyneuropathy to document autonomic nervous system involvement (Level B). Autonomic testing should be considered in the evaluation of patients with suspected autonomic neuropathies (Level B) and may be considered in the evaluation of patients with suspected distal SFSN (Level C). The combination of autonomic screening tests in the CASS should be considered to achieve the highest diagnostic accuracy (Level B).

Role of nerve biopsy in the evaluation of polyneuropathy. Nerve biopsy is generally accepted as useful in the diagnosis of inflammatory diseases of nerve such as vasculitis, sarcoidosis, CIDP, infectious diseases such as leprosy, or infiltrative disorders such as tumor or amyloidosis. ${ }^{3}$ Nerve biopsy is most valuable in mononeuropathy multiplex or suspected vasculitic neuropathy. There are no studies regarding the role of nerve biopsy in the evaluation of DSP although on occasion the above noted diseases may present in that fashion.

What is the usefulness of nerve biopsy in determining the etiology of distal symmetric polyneuropathy? Out of 50 articles judged to be relevant, no article attained a grade greater than Class IV. Most of the articles discussed the nerve biopsy findings in specific diseases, the clinical suspicion of which had prompted the biopsy. ${ }^{23-34}$ No article provided guidance regarding when to perform a nerve biopsy in the evaluation of DSP

Conclusions. There is no evidence to support or refute a conclusion regarding the role of nerve biopsy in the evaluation of DSP (Class IV).

Recommendations. No recommendations can be made regarding the role of nerve biopsy in determining the etiology of DSP (Level U).

Role of skin biopsy in the evaluation of polyneuropathy. Skin biopsy is being increasingly used to evaluate patients with polyneuropathy. The most common technique involves a $3 \mathrm{~mm}$ punch biopsy of skin from the leg. After sectioning by microtome, the tissue is immunostained with anti-protein-geneproduct 9.5 (PGP 9.5) antibodies and examined with immunohistochemical or immunofluorescent methods. This staining allows for the identification and counting of intraepidermal nerve fibers (IENF). PGP 9.5 immunohistochemistry has been validated as a reliable method for IENF density determination with good intra- and interobserver reliability in normal controls and patients with DSP. ${ }^{35-38}$

In March 2005, the European Federation of Neurological Societies (EFNS) published a guideline on the use of skin biopsy in peripheral neuropathy. ${ }^{35}$ This comprehensive review focused on the technical aspects of skin biopsy as well as normative data and correlations with other clinical, physiologic, and pathologic tools. The EFNS concluded that skin biopsy is a safe, validated, and reliable technique for the determination of IENF density. The major conclusion was that skin biopsy (IENF density) was diagnostically efficient at distinguishing polyneuropathy patients (including small fiber neuropathy) from normal controls. The EFNS guideline also reviewed 
the literature on IENF morphologic changes such as axonal swellings as a measure of distal symmetric polyneuropathy. ${ }^{35,39,40}$ The EFNS concluded that axonal swellings may be predictive of progression of polyneuropathy but further studies were needed to determine their diagnostic accuracy. ${ }^{35}$

What is the usefulness and diagnostic accuracy of skin biopsy in the evaluation of polyneuropathy? Beyond distinguishing asymptomatic normal controls from polyneuropathy patients, one clinical question not addressed by the EFNS guideline was the diagnostic accuracy of skin biopsy in distinguishing symptomatic patients with polyneuropathy from symptomatic patients without polyneuropathy. For example, in patients with painful feet, would skin biopsy accurately distinguish patients with polyneuropathy from patients with other conditions causing painful feet?

To address this separate question, a subgroup of the Polyneuropathy Task Force (J.D.E., R.A.L., D.H., G.L., M.P., and G.S.G.) independently reviewed the literature regarding the diagnostic accuracy of skin biopsy in DSP and in the SFSN form of DSP. To be considered for review, studies needed to determine IENF density in patients with and without polyneuropathy. Furthermore, the studies had to be presented in such a way calculation of the sensitivity and specificity of skin biopsy for polyneuropathy.

Nine studies met inclusion criteria. $36,39-40, \mathrm{e} 1-\mathrm{e} 6$ One was a prospective cohort survey of patients presenting with bilateral painful feet and normal strength, but skin biopsy was done only in those with normal NCS. ${ }^{\mathrm{e} 1}$ Patients with reduced IENF density and normalNCS were assumed to have painful small fiber neuropathies. However, the study did not compare the results of the IENF density to an independent reference standard to confirm the presence of small fiber neuropathy. Thus, for the purposes of determining the diagnostic accuracy of skin biopsy for polyneuropathy, this study was graded Class IV.

The remaining studies employed a case-control design. $36,39,40, \mathrm{e} 2-\mathrm{e} 6$ In these studies, the investigators performed skin biopsies on patients with established polyneuropathy and normal controls. No study included patients with conditions causing lower extremity pain or sensory complaints that might be confused with polyneuropathy. Thus, all studies had potential spectrum bias. Following the evidence classification scheme for studies of diagnostic accuracy, all of these studies were graded Class III.

All of the case control studies showed a significant reduction in IENF density in polyneuropathy patients as compared to controls. ${ }^{36,39,40, \mathrm{e} 2-\mathrm{e} 6}$ The sensitivity of decreased IENF density for the diagnosis of polyneuropathy was moderate to good (range 45 to
$90 \%)$. The specificity of normal IENF density for the absence of polyneuropathy was very good (range 95 to $97 \%$ ). Thus, the absence of reduced IENF density (using the clinical impression as the diagnostic reference standard) would not "rule out" polyneuropathy, but the presence of reduced IENF density would importantly raise the likelihood of polyneuropathy.

The form of DSP for which IENF assessment is particularly diagnostically attractive is SFSN for the following reasons: 1) IENF are the nerve terminals of somatic unmyelinated $\mathrm{C}$ fibers, which are hypothesized to be predominantly affected in SFSN. 2) There has been a lack of a direct objective measure of small fiber sensory nerves since objective measures of large fiber function (e.g., NCS) are by most definitions normal in SFSN. ${ }^{7}$ 3) Patients in whom SFSN is clinically suspected manifest with symptoms of small fiber sensory dysfunction (e.g., tingling, numbness, and neuropathic pain) but few objective signs, making it difficult to diagnose and to distinguish SFSN from non-neurologic causes of sensory complaints. ${ }^{\mathrm{e}}$

Since no validated objective gold standard exists for the diagnosis of SFSN, the authors considered whether demonstration of a pathologic lesion (small sensory fiber pathology on skin biopsy) should be the e facto diagnostic standard or whether a clinical impression of SFSN should be the independent reference standard. For the purposes of this parameter, a clinical impression of SFSN was adopted as the independent reference standard for calculation of sensitivity and specificity of IENF density in the detection of SFSN.

In order to assess the diagnostic accuracy of IENF density assessment for SFSN, the literature was surveyed for studies assessing IENF density in subjects with clinically suspected SFSN (symptoms or symptoms and signs of DSP but with normal NCS) and controls where the diagnostic accuracy of IENF density for clinically defined SFSN could be determined. Four Class III studies met these criteria. ${ }^{\mathrm{e} \text {,e8-e10 }}$ The sensitivity of IENF density assessment at the ankle for DSP with normal NCS was 58\% (20\% for subjects with symptoms but no signs of SFSN; $100 \%$ for subjects with symptoms and signs of SFSN), ${ }^{\text {e } 8}$ $90 \%,{ }^{\text {e6 }}$ and $24 \% .{ }^{\text {e9 }}$ In these studies, the specificity of the test ranged from $95 \%$ to $97.5 \%$. $^{\mathrm{e}, \mathrm{e} 8, \mathrm{e} 9}$ The other case control study found that among patients with symptoms of SFSN and an abnormal pinprick examination in the feet, but normal ankle reflexes, normal vibration sensibility, and normal NCS, an IENF density of $<8$ fibers $/ \mathrm{mm}$ at the dorsal foot provided a sensitivity of $88 \%$, a specificity of $91 \%$, a positive predictive value of 0.9 , and a negative predictive value of 0.83 for the diagnosis of SFSN. ${ }^{\text {e10 }}$

Conclusions. IENF density assessment using PGP 9.5 immunohistochemistry is a validated, reproduc- 
ible marker of small fiber sensory pathology. Skin biopsy with IENF density assessment is possibly useful to identify DSP which includes SFSN in symptomatic patients with suspected polyneuropathy (Class III).

Recommendations. For symptomatic patients with suspected polyneuropathy, skin biopsy may be considered to diagnose the presence of a polyneuropathy, particularly SFSN. (Level C)

RECOMMENDATIONS FOR FUTURE RESEARCH This comprehensive review reveals several weaknesses in the current approach to the evaluation of polyneuropathy and highlights opportunities for research.

- Autonomic testing. Autonomic testing can with a high degree of accuracy document autonomic system dysfunction in polyneuropathy. This is particularly relevant to small fiber polyneuropathy and the autonomic neuropathies. Research is necessary to determine whether the documentation of autonomic abnormalities is important in modifying the evaluation and treatment of polyneuropathy. Specific tests such as QSART can document small fiber (i.e., sudomotor axon) loss with a high degree of sensitivity, making the test useful to confirm the diagnosis of small fiber polyneuropathy. Since skin biopsy with determination of IENF density can also document small fiber loss, there is a need for studies that compare and correlate the two techniques.

- Nerve biopsy There are no studies of nerve biopsy in the evaluation of DSP. Although it would be useful to know the outcome of welldesigned prospective studies in this area, it is unlikely that such studies will be done.

- Skin biopsy. Skin biopsy with determination of IENF density is a technique that has come of age for the objective documentation of small fiber loss. This technique provides a unique opportunity for research in different varieties of neuropathy. Further studies are needed to characterize the diagnostic accuracy of skin biopsy in distinguishing patients with suspected polyneuropathy, particularly SFSN, from patients with sensory complaints or pain unrelated to peripheral neuropathy. Prospective studies with appropriate "other disease" controls should be done to assess the sensitivity, specificity, and predictive values of IENF density measurement to identify SFSN in patients with lower extremity pain or sensory complaints. A predetermined independent reference standard for the diagnosis of SFSN should be specifically stated in such studies.
- A case definition of SFSN should be developed. Investigators need to determine whether this case definition should be based upon clinical criteria, pathologic criteria (e.g., skin biopsy), or a combination of clinical, paraclinical, and pathologic criteria.

- The diagnostic accuracy of morphologic changes (e.g., axonal swellings) in the diagnosis of SFSN vs healthy controls and disease controls needs to be better defined.

- Studies exploring other uses for skin biopsy beyond identification and quantification of DSP and SFSN have been reported and should be further explored. Biopsies of glabrous skin and dermal skin include myelinated nerve fibers, and have been shown to have potential utility in the diagnosis of immune-mediated neuropathies, Charcot-Marie-Tooth, and related diseases. ${ }^{\text {e2 }}$ Other studies have employed skin biopsy for detection or monitoring of leprosy, hereditary amyloidosis, vasculitic neuropathy, and Fabry disease. ${ }^{\text {e11-e14 }}$ Additional studies are required to determine the usefulness of skin biopsy in the diagnosis and monitoring of these and other varieties of neuropathy.

Serial IENF density measurements and IENF regenerative capacity are being studied and used as outcome measures in therapeutic trials. ${ }^{\text {e15,e16 }}$ Further studies are needed to validate and determine the value of skin biopsy for this purpose.

\section{AUTHORS' AFFILIATIONS}

From the Louisiana State University Health Sciences Center (J.D.E., A.J.S.), New Orleans; University of Kansas (G.S.G.), Kansas City; University of Washington (G.F.), Seattle; Providence Health System (G.T.C.), Southwest Washington; St. Louis University School of Medicine (L.J.K.), St. Louis, MO; Dartmouth Hitchcock Medical Center (J.A.C.), Lebanon, NH; University of Pennsylvania School of Medicine (A.K.A.), Philadelphia; Baylor College of Medicine (K.S., J.R.L.), Houston, TX; Weill Medical College of Cornell (N.L.), New York, NY; Wayne State University School of Medicine (R.A.L.), Detroit, MI; Mayo Clinic (P.A.L.), Rochester, MN; Loyola University Chicago Stritch School of Medicine and the Hines VAH (M.A.F.), IL; University of Rochester Medical Center (D.H.), NY; University of North Carolina (J.F.H.), Chapel Hill; Fondazione IRCCS National Neurological Institute "Carlo Besta" (G.L.), Milan, Italy; California Pacific Medical Center (R.G.M.), San Francisco; and Johns Hopkins Medical Institutions (M.P.), Baltimore, MD.

\section{DISCLOSURE}

J.D.E. holds financial interests in Pfizer and has received research support from Wyeth and Pfizer. G.S.G. has received speaker honoraria from Pfizer, GlaxoSmithKline, and Boehringer Ingelheim and served on the IDMC Committee of Ortho-McNeil. He estimates that $<2 \%$ of his clinical effort is spent on EMG and EEG. G.F., A.K.A., and K.S. have nothing to disclose. G.T.C estimates that $30 \%$ of his clinical effort is spent on EMG. J.A.C. has received speaker honoraria from Athena Diagnostics and estimates that $40 \%$ of his clinical effort is spent on EMG/NCS, $10 \%$ on autonomic testing, and $10 \%$ on botulinum toxin injections. L.J.K. has received speaker honoraria from American Medical Seminars, Cross Country Education, Therapath Laboratories, and CME, LLC, and holds equity in Passnet Air Ambulance. He estimates 25\% of his clinical effort is spent on NCS/EMG, $4 \%$ on skin biopsy for nerve fiber counting, and $8 \%$ 
on autonomic studies, and has received payment for expert testimony in legal proceedings. J.R.L. holds financial interests in Athena Diagnostics and has received research funding from NIH/NEI, NIH/NIDCR, Charcot-Marie-Tooth Association, and the March of Dimes. N.L. serves as a consultant for Talecris Biopharmaceuticals and Quest Diagnostics, receives royalties from Athena Diagnostics, and holds equity and is a partner in Therapath LLC. He is the Medical and Scientific Director for the Neuropathy Association, estimates that $<1 \%$ of his clinical effort is spent on skin biopsy, and has received research support from Talecris Biotherapeutics. R.A.L. has consulted for Talecris and has received research funding from MDA, Baxter Pharmaceuticals, and CMTA. He estimates that $33 \%$ of his clinical effort is spent on electromyography. He has received payment for expert testimony regarding the use of IVIg in CIDP and neuropathic pain after breast reduction. P.A.L. estimates $25 \%$ of his clinical effort is spent on autonomic reflex screening. D.H. has received research funding from NIH, Astellas Pharmaceutical Company, and MDA/ CMT Association. He estimates that $25 \%$ of his clinical effort is spent on EMG and $20 \%$ on skin biopsies. J.F.H. holds financial interests in FEMI, Johnson \& Johnson, Pfizer, and General Electric. He estimates that 40\% of his clinical effort is spent on EMG/NCS. G.L. holds financial interests in GlaxoSmithKline and Formenti-Grunenthal. In addition, he has received research funding from Pfizer, Formenti-Grunenthal, Italian Ministry of Health, and Regione Lombardia. He estimates that $25 \%$ of his clinical effort is spent in an outpatient pain center, $25 \%$ on out- and inpatient clinical examination, $25 \%$ on skin biopsy examination, and $25 \%$ on research. R.G.M. holds financial interests in Celgene, Knopp Neurosciences, Medivation, Teva Neuro, Taiji Biomedicals, and Translational Genomics. M.P. serves on the scientific advisory board of GSK, the editorial board of Journal of the Peripheral Nervous System, the speake bureau of Pfizer and participated in the Joslin diabetes CME programs. He has received research funding from Astellas Pharma and Mitsubishi Pharma and reads clinical skin biopsies, runs an EMG lab, patients with peripheral nerve diseases. A.J.S. has recery expert testimony in the possible neurotoxic injury of the peripheral nerve.

\section{DISCLAIMER}

The diagnosis and evaluation of polyneuropathy is complex. The practice parameter is not intended to replace the clinical judgment of experienced physicians in the evaluation of polyneuropathy. The particular kinds of tests utilized by a physician in the evaluation of polyneuropathy depend upon the specific clinical situation and the informed medical judgment of the treating physician.

This statement is provided as an educational service of the AAN, AANEM, and AAPM\&R. It is based upon an assessment of current scientific and clinical information. It is not intended to include all possible proper methods of care for a particular neurologic problem or all legitimate criteria for choosing to use a specific test or procedure. Neither is it intended to exclude any reasonable alternative methodologies. The AAN, $A A N E M$, and $A A P M \& R$ recognize that specific care decisions are the prerogative of the patient and physician caring for the patient, based on all of the circumstances involved.

\section{APPENDIX 1}

Quality Standards Subcommittee (AAN): Jacqueline French, MD, FAAN (chair); Charles E. Argoff, MD; Eric Ashman, MD; Stephen Ashwal, MD, FAAN (ex-officio); Christopher Bever, Jr., MD, MBA, FAAN; John D. England, MD, FAAN (QSS facilitator); Gary M. Franklin, MD, MPH, FAAN (ex-officio); Deborah Hirtz, MD (ex-officio); Robert G. Holloway, MD, MPH, FAAN; Donald J. Iverson, MD, FAAN; Steven R. Messé, MD; Leslie A. Morrison, MD; Pushpa Narayanaswami, MD, MBBS; James C. Stevens, MD, FAAN (ex-officio); David J. Thurman, MD, MPH (ex-officio); Dean M. Wingerchuk, MD, MSc, FRCP $(C)$; and Theresa A. Zesiewicz, MD, FAAN

\section{APPENDIX 2}

Practice Issues Review Panel (AANEM): Yuen T. So, MD, PhD (chair); Michael T. Andary, MD; Atul Patel, MD; Carmel Armon, MD; David del Toro, MD; Earl J. Craig, MD; James F. Howard, Jr, MD; Joseph V. Campellone Jr., MD; Kenneth James Gaines, MD; Robert Werner, MD; and Richard Dubinsky, MD.

\section{APPENDIX 3}

Practice Guidelines Committee (AAPM\&R): Dexanne B. Clohan, MD (chair); William L. Bockenek, MD; Lynn Gerber, MD; Edwin Hanada, MD; Ariz R. Mehta, MD; Frank J. Salvi, MD, MS; and Richard D. Zorowitz, MD.

Received April 24, 2008. Accepted in final form August 29, 2008.

\section{REFERENCES}

1. England JD, Gronseth GS, Franklin G, et al. Distal symmetric polyneuropathy: a definition for clinical research: report of the American Academy of Neurology, the American Association of Electrodiagnostic Medicine, and the American Academy of Physical Medicine and Rehabilitation. Neurology 2005;64:199-207.

2. Martyn CN, Hughes RAC. Epidemiology of peripheral neuropathy. J Neurol Neurosurg Psychiatry 1997;62:310-318.

3. England JD, Asbury AK. Peripheral neuropathy. Lancet 2004;363:2151-2161.

4. Low PA, Vernino S, Suarez G. Autonomic dysfunction in peripheral nerve disease. Muscle Nerve 2003;27:646-661.

5. Singer W, Spies JM, McArthur J, et al. Prospective evaluation of somatic and autonomic small fibers in selected neuropathies. Neurology 2004;62:612-618. (Class III)

6. Dyck PJ, Karnes JL, O’Brien PC, Litchy WJ, Low PA, Melton LJ. The Rochester Diabetic Neuropathy Study: reassessment of tests and criteria for diagnosis and staged severity. Neurology 1992;42:1164-1170. (Class II) Low PA, Denq JC, Opfer-Gehrking TL, Dyck PJ, O’Brien PC, Slezak JM. Effect of age and gender on sudomotor and cardiovagal function and blood pressure response to tilt in normal subjects. Muscle Nerve 1997;20:1561-1568. (Class II)

8. Ziegler D, Dannehl K, Muhlen, Spuler M, Gries FA. Presence of cardiovascular autonomic dysfunction assessed by spectral analysis, and standard tests of heart rate variation and blood pressure response at various stages of diabetic neuropathy. Diabet Med 1992;9:806-814.

9. Low PA. Composite Autonomic Scoring Scale for laboratory quantification of generalized autonomic failure. Mayo Clin Proc 1993;68:748-752. (Class II)

10. Ebert TJ, Morgan BJ, Barney JA, Denahan T, Smith JJ. Effects of aging on baroreflex regulation of sympathetic activity in humans. Am J Physiol 1992;263:798-803.

11. Trimarco B, Volpe M, Ricciardelli B, et al. Valsalva maneuver in the assessment of baroreflex responsiveness in borderline hypertensives. Cardiology 1983;70:6-14.

12. Vogel ER, Sandroni P, Low PA. Blood pressure recovery from Valsalva maneuver in patients with autonomic failure. Neurology 2005;65:1533-1537. (Class II)

13. Schrezenmaier C, Singer W, Muenter-Swift N, Sletten D, Tanabe J, Low PA. Adrenergic and vagal baroreflex sensitivity in autonomic failure. Arch Neurol 2007;64:381386. (Class II)

14. Low PA, Walsh JC, Huang C, McLeod JG. The sympathetic nervous system in diabetic neuropathy: a clinical and pathological study. Brain 1975;98:341-356.

15. Fealey RD, Low PA, Thomas JE. Thermoregulatory sweating abnormalities in diabetes mellitus. Mayo Clin Proc 1989;64:617-628.

16. Low PA, Caskey PE, Tuck RR, Fealey RD, Dyck PJ. Quantitative sudomotor axon reflex test in normal and neuropathic subjects. Ann Neurol 1983;14:573-580. 
17. Stewart AG, Low PA, Fealey RD. Distal small fiber neuropathy: results of tests of sweating and autonomic cardiovascular reflexes. Muscle Nerve 1992;15:661-665. (Class III)

18. Tobin K, Guliani MJ, LaComis D. Comparison of different modalities for detection of small fiber neuropathy. Clin Neurophysiol 1999;110:1909-1912. (Class III)

19. Novak V, Freimer ML, Kissel JT, et al. Autonomic impairment in painful neuropathy. Neurology 2001;56:861868. (Class III)

20. Low PA, Zimmerman BR, Dyck PJ. Comparison of distal sympathetic with vagal function in diabetic neuropathy. Muscle Nerve 1986;9:592-596.

21. Low PA, Opfer-Gehrking TL, Proper CJ, Zimmerman I. The effect of aging on cardiac autonomic and postganglionic sudomotor function. Muscle Nerve 1990;13:152-157.

22. Low PA, Neumann C, Dyck PJ, Fealey RD, Tuck RR. Evaluation of skin vasomotor reflexes by using laser Doppler velocimetry. Mayo Clin Proc 1983;58:583-592. (Class III)

23. Argov Z, Steiner I, Soffer D. The yield of sural nerve biopsy in the evaluation of peripheral neuropathies. Acta Neurol Scand 1989;79:243-245.

24. Bosboom WMJ, VanderBerg LH, Franssen H, et al. Diagnostic value of sural nerve demyelination in chronic inflammatory demyelinating polyneuropathy. Brain 2001; 124:2427-2438.

25. Chia L, Fernandez A, Lacroix C, Adams D, Planté V, Said G Contribution of nerve biopsy findings to the diagnosis of disabling neuropathy in the elderly: a retrospective review of 100 consecutive patients. Brain 1996;119:1091-1098.

26. Deprez M, Ceuterick-DeGroote C. Clinical and neuropathological parameters affecting the diagnostic yield of nerve biopsy. Neuromuscul Disord 2000;10:92-98.

27. Deprez M, Ceuterick-DeGroote C, Schoenen J, Reznik M, Martin JJ. Nerve biopsy: indications and contribution of the diagnosis of peripheral neuropathy. Acta Neurol Belg 2000;100:162-166.

28. Flachenecker P, Janka M, Goldbrunner R, Toyka KV. Clinical outcome of sural nerve biopsy: a retrospective study. J Neurol 1999;246:93-96.

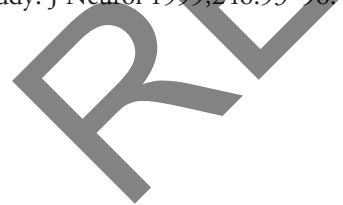

29. Gabriel CM, Howard R, Kinsella N, et al. Prospective study of the usefulness of sural nerve biopsy. J Neurol Neurosurg Psychiatry 2000;69:442-446.

30. Molenaar DSM, Vermeulen M, de Haan R. Diagnostic value of sural nerve biopsy in chronic inflammatory demyelinating polyneuropathy. J Neurol Neurosurg Psychiatry 1998;64:84-89.

31. Rappaport WD, Valente J, Hunter GC, et al. Clinical utilization and complications of sural nerve biopsy. Am J Surg 1993;166:252-256.

32. Said G. Indications and value of nerve biopsy. Muscle Nerve 1999;22:1617-1619.

33. Said G. Value of nerve biopsy. Lancet 2001;357:12201221.

34. Said G. Indications and usefulness of nerve biopsy. Arch Neurol 2002;59:1532-1535.

35. Lauria G, Cornblath DR, Johansson O, et al. EFNS Guidelines on the use of skin biopsy in the diagnosis of peripheral neuropathy. Eur J Neurol 2005;12:1-12.

36. McArthur JC, Stocks EA, Hauer P, Cornblath DR, Griffin JW. Epidermal nerve fiber density: normative reference range and diagnostic efficiency. Arch Neurol 1998;55: 1513-1520. (Class III)

Goranson LG, Mellgren SI, Lindal S, Omdal R. The effect of age and gender on epidermal nerve fiber density. Neurology 2004;62:774-777.

Smith AG, Howard JR, Kroll R, et al. The reliability of skm biopsy with measurement of intraepidermal nerve fiber density. J Neurol Sci 2005;228:65-69.

39. Lauria G, Morbin M, Lombardi R, et al. Axonal swellings predict the degeneration of epidermal nerve fibers in painful neuropathies. Neurology 2003;61:631-636. (Class III)

40. Herrmann DN, McDermott MP, Henderson D, Chen L, Akowuah K, Schifitto G, and The North East AIDS Dementia (NEAD) Consortium. Epidermal nerve fiber density, axonal swellings and QST as predictors of HIV distal sensory neuropathy. Muscle Nerve 2004;29:420-427. (Class III) 


\section{Neurology}

Practice Parameter: Evaluation of distal symmetric polyneuropathy: Role of autonomic testing, nerve biopsy, and skin biopsy (an evidence-based review) [RETIRED]: Report of the American Academy of Neurology, American Association of Neuromuscular and

Electrodiagnostic Medicine, and American Academy of Physical Medicine and

$$
\text { Rehabilitation }
$$

J. D. England, G. S. Gronseth, G. Franklin, et al.

Neurology 2009;72;177-184 Published Online before print December 3, 2008

DOI 10.1212/01.wnl.0000336345.70511.0f

This information is current as of December 3, 2008

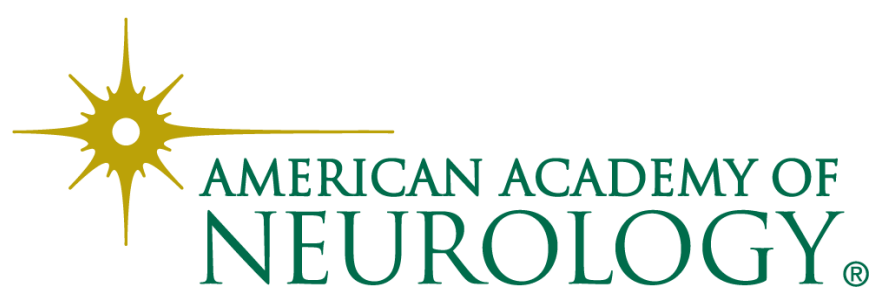




\section{Updated Information \& Services}

\section{Supplementary Material}

\section{References}

Citations

Permissions \& Licensing

\section{Reprints}

including high resolution figures, can be found at:

http://n.neurology.org/content/72/2/177.full

Supplementary material can be found at: http://n.neurology.org/content/suppl/2010/09/12/01.wnl.0000336345.7 0511.0f.DC5 http://n.neurology.org/content/suppl/2009/07/08/01.wnl.0000336345.7 0511.0f.DC3

http://n.neurology.org/content/supp1/2009/11/05/01.wnl.0000336345.7 0511.0f.DC4

http://n.neurology.org/content/suppl/2008/12/03/01.wnl.0000336345.7 0511.0f.DC1

http://n.neurology.org/content/suppl/2009/01/11/01.wnl.0000336345.7 0511.0f.DC2

This article cites 40 articles, 10 of which you can access for free at: http://n.neurology.org/content/72/2/177.full\#ref-list-1

This article has been cited by 20 HighWire-hosted articles: http://n.neurology.org/content/72/2/177.full\#\#otherarticles

Information about reproducing this article in parts (figures,tables) or in its entirety can be found online at:

http://www.neurology.org/about/about_the_journal\#permissions

Information about ordering reprints can be found online:

http://n.neurology.org/subscribers/advertise

Neurology ${ }^{\circledR}$ is the official journal of the American Academy of Neurology. Published continuously since 1951, it is now a weekly with 48 issues per year. Copyright . All rights reserved. Print ISSN: 0028-3878. Online ISSN: 1526-632X.

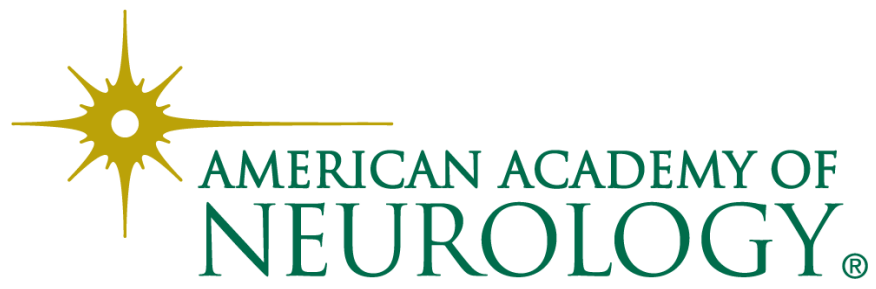

